* Mestranda em Direito junto a Universidade Federal de Santa Maria (UFSM). E-mail: laranunes7@hotmail.com ** Doutor em Direito pela Universidade Federal de Santa Catarina (2010).

*** Mestrando em Direito Público pela Universidade do Vale do Rio dos Sinos (UNISINOS).

\section{O controle do tempo como condição de possibilidade para o sistema de controle penal na sociedade neo-tecnológica}

\author{
ThE CONTROL OF TIME AS A CONDITION OF THE \\ POSSIBILITY FOR CONTROL SYSTEM CRIMINAL IN \\ NEO-TECHNOLOGY SOCIETY
}

\author{
Larissa Nunes Cavalheiro * \\ Rafael Santos de Oliveira ** \\ Fernando Hoffmam ***
}

Resumo: A evolução do conceito de tempo está umbilicalmente ligada à evolução dos modelos sociais. Dado ao inerente aumento da complexidade do tecido social, o referido conceito, ao longo da história, seguiu o mesmo rumo, de acordo com o momento civilizacional de cada sociedade. Tal processo se vê acelerado nos dias atuais, a partir da evolução tecnológica atinente à nossa modernidade - pós-modernidade, modernidade líquida, outra modernidade, entre demais terminologias, do período histórico que fecha a explanação do primeiro momento do presente trabalho. Após, objetivou-se levantar questões acerca de uma leitura conjunta entre o tempo e a prisão, evidenciando as suas implicações, para então abordar questões oriundas do monitoramento eletrônico, diante do paradigma contemporâneo temporal da instantaneidade e da aceleração. Logo, em face deste novo cenário, se faz necessário repensar o Direito e, neste bojo, o paradigma punitivo sobre o qual está construído o sistema penal atual. Desta forma, em específico, se abordou o monitoramento eletrônico como uma possibilidade eficaz de releitura do sistema e, não de seu aprimoramento.

Palavras-chave: Tempo; Prisão; Monitoramento Eletrônico.

Abstact: The evolution of the concept of time is umbilically linked to the evolution of social models. Given the increased complexity inherent in of the social, that concept, throughout history,followed the same course, according to the time of every civilized society. This process is currently accelerating today, as regards the technological evolution of our modernity - post modernity, liquid modernity, another modernity between other terminologies, the historical period that closes the explanation of the first moment of this work. After had the objective to raise questions about a reading between time and 


\section{INTRODUÇÃO}

$\mathrm{Na}$ atualidade, percebe-se um Direito ainda ancorado em velhos paradigmas da modernidade, com isso, abstraído, muitas vezes, da realidade social a qual pertence. Tal circunstância não é diferente, e porque não, mais acentuada, quando se atenta ao Direito Penal, tanto no aspecto material, quanto processual. Também - e por causa disso -, em específico, não difere quando se fala em paradigma punitivo ou sistema de controle penal.

Nesta maré, nota-se um descompasso entre o sistema de penas consolidado e a lógica espaço-temporal instantânea da sociedade neotecnológica, bem como, com o sistema jurídico-punitivo, que se espera compatível com o Estado Democrático de Direito.

Desta forma, o escopo do presente trabalho é realizar uma releitura do sistema de controle penal, readequando-o ao paradigma temporal contemporâneo, compatibilizando-o com o mesmo. Para tanto, primeiramente, são feitos apontamentos acerca do tempo, em diferentes períodos sociais, delineando um entendimento acerca da temporalidade (sen)tida em cada época. Após essa apresentação das noções de tempo, que partem da Antiguidade Clássica grega até a fluidez dos atuais dias, se entrelaça o tempo no que tange ao sistema prisional - prisão. Desse ponto, parte-se para uma explanação com o intuito de expor o tempo como elemento de operacionalização da punição.

Após essas questões, que se vislumbra, no presente trabalho, o uso do monitoramento eletrônico de presos como uma possibilidade de readequação do paradigma punitivo-temporal, de humanização da pena e, de desencarceramento, não se tratando, num aumento do sistema de controle penal.

\section{OS ANTIGOS PARADIGMAS TEMPORAIS E O TEMPO DA/ NA SOCIEDADE CONTEMPORÂNEA}

São muitos os questionamentos sobre o "tempo", onde, da mesma forma, são várias as questões propostas, desde Platão e Aristóteles, passando por Galileu e Copérnico; Newton e o tempo idealizado e a ruptura temporal proposta pela relatividade de Einstein. E em verdade, o que seria o "tempo", enquanto instituto - se assim pode ser denominado -, será ontem, hoje, amanhã? Será estático, ideal, móvel, constante ou inconstante? 
O tempo, enquanto categoria social permeia por completo o horizonte relacional do ser humano, instituindo um "tempo de convívio", que orienta e condiciona a prática social. Certamente, esta relação tempo e sociedade não se dá de maneira contínua, pois sofre os desmantelamentos e reconstruções, pelos quais passa o meio de convívio, ou seja, pelas modificações do "estar-se em sociedade" e, sobremodo, do "estar-se em determinada época" - estar-se em determinado tempo.

Deste modo, antes de dizer que o tempo, enquanto "objeto" assumiu diversas roupagens ao longo das épocas, é necessário referir que neste trabalho será tratado com uma possibilidade inserida em um processo civilizacional. Ou seja, há uma adaptação do que consiste o tempo, de acordo com determinada sociedade, em determinada época de uma civilização (ELIAS, 1998, passim). Quando aqui, se faz referência a uma adaptabilidade do conceito de tempo a determinada época, pretende-se dizer que o tempo sofre os influxos da sociedade e do evoluir social. Intenta-se, que o tempo em uma sociedade mais primitiva possui projeções em menor escala, no modo de ser desta sociedade. No entanto, com o aumento da complexidade em determinada zona de convívio social, o tempo passa a ser uma categoria operacional de grande relevância, para o modo de ser daqueles indivíduos em sociedade (ELIAS, 1998, p.36-43).

Neste passo, para se trabalhar a importância do tempo - enquanto "objeto" -, para as relações de convivência em sociedade, bem como, no que tange ao Direito, se faz necessário uma digressão aos tempos idos da Antiguidade. A partir de tal época, que se começa a discutir a existência e participação do tempo na vida humana.

Assim, com fundamento na cosmologia grega, primeiramente trabalhase com um ideal de perfeição e com um mundo idealizado dado a eternidade. Enfatizava-se a estada em um mundo imutável, não tendo desse modo o tempo, sequer como uma categoria. Neste momento histórico está em uma condição de "não-tempo", ou seja, não há passagem do tempo, não há estar no tempo, mas sim, apenas o pertencimento a uma vida de certezas e imobilidades, a partir do ideal de perfeição cosmológico (PINTO, 2002, p.1112).

No entanto, com Platão e Aristóteles começa a se pensar a questão do tempo de maneira diferente - começa a se pensar (n)o tempo. Este passa a existir, mesmo não sendo ainda como o "conhecemos" hoje. Para Platão estaria o tempo - já aqui enquanto categoria -, inserido no mundo 
sensível, tendo assim uma realidade diversa da do mundo. Dessa forma, pode ser visto como uma categoria imaginária ligada ao universo e, concebido como uma projeção da eternidade (PINTO, 2002).

Aristóteles amplia a concepção temporal de Platão, começando a delinear a inserção do tempo no mundo real. Ao relacionar tempo e movimento Aristóteles confere vestimenta de realidade à categoria temporal. Ainda que eterno, passa a fazer parte do mundo e, embora real, permanece imutável e relacionado diretamente ao ser - ou ao movimento, a algo tendo assim, mantida a idéia - que perdurou por toda a Idade Média - de tempo cíclico (PINTO, 2002, p.13-15).

Neste caminho, chega-se a modernidade forjando-se a partir das ideias newtonianas - sobremodo - uma visão atemporal do tempo. Newton absolutiza o tempo, positiva-o, dentro de uma lógica espaço-temporal, concebida sob a égide da certeza. Aqui, apesar de já se estar no tempo, se está num tempo destemporalizado e fora do mundo, pois absoluto, inerte. Para Moretto (2005, p.4),

Estamos de fronte a um mundo sem novidades, pois tudo esta programado, uma vez que, conhecidas as condições iniciais, saberemos a condição futura, se é que podemos tratar de passado e futuro quando ambos têm o mesmo papel. Quer se dizer com isso que teríamos um universo estático, sem criação e previamente montado, onde a natureza e o homem em nada influenciariam, pois, se podemos saber o futuro conhecendo o presente, para esse se mostrar não pode sofrer perturbações.

Newton tira o tempo do mundo - assim como a teoria jurídica moderna tira do mundo o Direito - e o coloca em outra dimensão ideal(izada), fazendo com que o tempo transcorra uniforme do passado ao futuro e, tornando-o reversível. Ele inventou, portanto, um tempo escrupulosamente neutro, onde a sua mecânica reduz o passado e o futuro apenas ao momento presente (KLEIN, 1995, p.25).

Neste passo, tal construção a respeito do "temporal", faz com que o tempo perca - não tenha - consistência e realidade. O tempo newtoniano flui sempre constantemente, independente do que aconteça no mundo, criando assim uma dimensão temporal a-histórica, onde as condições histórico-temporais do ser - do mundo - serão sempre as mesmas (KLEIN, 1995, p.27). 
Constitui-se assim, um momento histórico onde a imobilidade, além de ser a regra, não pode ser desfeita, pois as dimensões temporais - leia-se passado, presente e futuro - são tratadas como uma só e, em estando no presente já se conheceria o passado. Deste modo, natureza e ser humano não tem influência alguma no fluir temporal, no passar do tempo, esse segue seu "rumo estático" e passivo a todo e qualquer acontecimento mundano (MORETTO, 2005, p.4).

Mas, eis que surge Einstein e sua Teoria da Relatividade. Assim, passa o tempo a ser relativo a partir do observador. Einstein, afirma que tanto espaço, quanto tempo são relativos e, em verdade o que é constante é a velocidade da luz (MORETTO, 2005, p.13). Não há mais uma simultaneidade temporal, a relação tempo-espaço depende do observador, assim, tais eventos são descritos, a partir da existência diretamente relacionada e dialogal do espaço-tempo (PINTO, 1998, p.40-41). Dessa forma, não mais absoluto é o tempo, dependendo da ação do observador sobre o seu "acontecimento" no mundo - embora aqui, ainda não se tenha uma ruptura total, pois ainda se mantêm a noção de determinismo.

Por manter-se ainda a referida noção do tempo, é que o sujeito moderno acaba por racionalizar este tempo, tornando-o inócuo e indiferente ao curso da vida. Tal racionalização - que permeia toda a construção paradigmática moderna -, surge assentada no modo de produção capitalista e, num primeiro momento, no aprisionamento do "tempo humano" pelo o ambiente de trabalho - pelo ambiente da fábrica.

É com base nesse novo movimento liberal-capitalista, que os modelos de produção e, sobremodo, a força de trabalho veem-se sobre a ótica da ruptura e da reconstrução de padrões. Institui-se como padrão produtivo a inserção do indivíduo, em uma rotina "trabalhadora" alienada e alienante, em que o seu "tempo cotidiano" perde totalmente as cores, tornando o indivíduo - nesse momento já trabalhador livre - um ser para o trabalho (MORAIS, 1998, p.22).

Claramente a relação tempo-trabalho ocorre de modo dominadodominante. Neste momento da história, o tempo enquanto instituição social se vê instituinte e institucionalizado do/pelo modo de produção capitalista. Passa a ser uma espécie de instituição regradora do convívio social, controlando-o e disciplinando-o para o trabalho, bem como, produzindo um senso de autodisciplinamento do homem para o trabalho - para o estar em sociedade. Neste ponto, o "tempo do trabalho" passa a sustentar toda a 
prática social e a ditar os padrões do estar-se em sociedade (ALVES, 2008, p.56-57).

A sensação de se estar no tempo de diversas formas é apagada do horizonte de sentidos - de sentimentos - do ser humano nesse momento histórico. Não há porque se questionar sobre o começo e o fim dos processos, não é dado ao sujeito na modernidade industrial à possibilidade de se perguntar "quando" alguma coisa ocorre. Mesmo quando não inserido no ambiente da fábrica - ou qualquer outro ambiente disciplinarmente controlado -, só há uma dimensão possível para ocorrer algo e, "quando" isso ocorrer estará eternamente em um universo controlado(r) (ELIAS, 1998, p.59).

Por certo, este paradigma moderno sofre uma drástica ruptura, sobretudo, a partir da segunda metade do século XX. Após a Segunda Guerra Mundial, a sociedade adentra um momento de ebulição produtivo-tecnológica, que joga o ser em um espaço reordenado novamente pelos modos de produção. No entanto, agora a velocidade aumenta e o compasso produtivotecnológico caminha de forma acelerada.

Assim, já que não há tempo universalizado e o tempo transcorre, esta modernidade que aprisionou o tempo de vida do ser humano através do trabalho, dá lugar a um novo acontecer histórico. Surge a pós-modernidade constituída de uma visão inovadora de mundo e erguida sobre os pilares nada sólidos do começo do século XX.

Neste passo, enquanto a modernidade era pesada, sólida, (in)coberta por certezas objetificantes e, caracterizada pela falta de movimento, é a pós-modernidade fluída, leve, envolta na subjetividade das incertezas e caracterizada pelo constante movimento de suas instituições, sejam estas jurídicas, políticas ou sociais. Este espaço líquido passa a ser o habitat do acontecer social, onde o tempo da sociedade, por evidente, também será líquido e, assim sendo, passa a redirecionar a relação tempo-sociedade - e suas instituições (BAUMAN, 2001, p.33-35).

Assim, temporalmente, os conceitos desta nova modernidade são formatados sob a égide da provisoriedade. A "modernidade líquida" (BAUMAN, 2001, p.33-35), abandona os postulados da certeza e da previsibilidade, para (re)fundar paradigmaticamente a noção de conhecimento e, de estar no mundo. O certo deve ser trocado pelo previsível, o estático deve ser trocado pelo movimento, bem como, o método, deve ser trocado pelas formas de mediação social (GAUER, 2004, p.6). 
Tal situação é acentuada pelo advento de novas tecnologias, que mudam completamente a lógica espaço-temporal, bem como, a lógica de acontecimento do estar em sociedade. Desta forma, tempo e espaço rompem-se, e, o tempo, passa a ser condição de possibilidade para a "conquista" do espaço. A lógica temporal domina a contemporaneidade e está fundada nesse momento sob a ótica da aceleração (BAUMAN, 2001, p.130-131). Conforme D’Maral (2003, p.20),

A tecno-logia concebida como o grande acontecimento fundador da cultura contemporânea é um modo de compreensão do mundo que é simultaneamente o movimento da sua transformação. O mundo só se compreende à proporção que está em processo de mudança: a prática e a teoria, a verdade e a ação, o conhecimento e a técnica condicionam-se reciprocamente de tal maneira, que são os progressos técnicos que tornam possíveis os avanços científicos; e são concepções científicas que exigem certos desenvolvimentos técnicos; tudo se enquadrando num só grande movimento de compreensão e transformação do mundo, regido por uma outra lógica, que não mais a da anterioridade da verdade em relação à transformação, ou da teoria em relação à prática. Trata-se da lógica da simultaneidade, do fazer que conhece e do conhecimento que transforma.

Assim, deve o sistema jurídico estar inserido nessa nova realidade do atual momento histórico. O Direito não pode ficar refratário a estas modificações da esfera social, bem como, não pode o sistema punitivo direito penal e processo penal - seguirem ligados à lógica punitivista moderna, devendo reordenar-se a relação tempo e pena. Diante desse entendimento, é que se passa a desenvolver o próximo momento do presente trabalho, evidenciando a condição do tempo em operacionalizar a punição.

\section{O TEMPO DA PRISÃO E O TEMPO NA PRISÃO: O CONTROLE DO TEMPO COMO PARADIGMA PUNITIVO}

Inserida nesse contexto temporal, que sofre constantes modificações até os dias de hoje, a pena sempre trouxe em si um forte sentido de perda ou manipulação do tempo. Sempre, baseou-se numa escala temporal, que procurou fixar uma proporcionalidade entre crime e tempo de pena, propiciando um verdadeiro espaço matemático de/para aplicação do direito (MESSUTI, 2003, p.27). 
Já na Idade Média até meados do século XVIII, se pode constatar na prática dos suplícios - como punição, como pena - a ação do tempo na prática em si. A pena de passar pelo suplício, de certa forma, se dá num curto espaço temporal, onde, no entanto, o "tempo punitivo" - da punição , se torna por demais alongado, dada a prática torturante na qual se cristaliza o suplício (FOUCAULT, 1994, p.11-14).

Quando se abandona a penalização através do suplício - visto como manipulação do corpo - urge a adoção de um novo tipo de pena. Tal mudança se dá com o advento da Revolução Industrial e, a modificação no tipo de criminalidade produzida pela sociedade moderna - agora uma sociedade urbana.

Com o deslocamento das populações do campo pra a cidade, a consolidação do ideário burguês e, a formação do "segundo capitalismo", forja uma criminalidade patrimonial, ou seja, os alvos dos criminosos deixam de serem as pessoas - diretamente - e passam a ser seu patrimônio. Ao invés atentar-se contra a vida, que predominava num primeiro momento, passa a se atentar contra bens, direitos.

Deste modo, na esteira da dominação do tempo social pela indústria, o indivíduo passa a ser visto como um objeto, que faz a engrenagem funcionar, uma vez que, os meios de produção capitalista necessitam de um trabalhador temporalmente disciplinado e alienado do contexto de ser-estar no mundo. Torna-se o único contexto aceitável na lógica do capitalismo industrial, o ser-estar no trabalho - a trabalhar -, estabelecendo-se assim uma reconfiguração do processo temporal, por meio de um estar-no-tempo disciplinado de acordo com o aparato produtivo (MORAIS, 1998, p.27). Punitivamente, domina-se o tempo social por meio da estrutura prisional, que neste momento histórico, deveria ser a responsável não só pela punição, como também, pela prevenção de novos crimes.

Logo, a pena de prisão é criação de uma sociedade racionalizada e racionalizadora, que buscou com ela, assim como, com as fábricas, racionalizar a ação - o transcurso - do tempo. Na Revolução Industrial, com o advento das fábricas, aprisiona-se o tempo social e transforma-o em tempo de trabalho. No cárcere, aprisiona-se o tempo de convívio humano e o transforma em tempo de punição (MESSUTI, 2003, p.42-43). Complementando tal entendimento, afirma Carvalho (2008, p.3): 
[...] se as agências de controle social são inseridas na burocracia com os objetivos de gestão dos desvios (caráter preventivo) e punição dos delitos (caráter repressivo), o direito (penal), ao pretender-se científico, recepciona o estatuto e a programação do racionalismo cartesiano. Nos passos das demais áreas das ciências naturais, é lançado na grande aventura da Modernidade: elaborar tecnologia (racionalidade instrumental) direcionada ao progresso e ao avanço social, de forma a conquistar condições de felicidade individual e bem-estar comunitário. A expectativa das comunidades científica e política em relação à ciência jurídico-penal não é outra, portanto, que a de desenvolver instrumentos capazes de erradicação do resto bárbaro que insistentemente emerge na cultura. Associada com a noção de crime, a violência impede a constituição da civilização, motivo pelo qual este último obstáculo deve ser extirpado.

O tempo passa a ter seu sentido coercitivo potencializado por estas instituições racionalizadoras da prática social. No que tange à pena, a lógica punitivo-temporal é invertida. Enquanto na concepção da pena como suplícios - castigos corporais - o tempo de execução da pena - de execução do suplício - era menor.Na ótica prisional, conforme a gravidade do crime, quanto mais grave for o crime, maior será o tempo de execução da pena maior será o tempo de prisão. Em suma, o tempo - o passar do tempo - é que opera(cionaliza) a punição (FOUCAULT, 1994, p.96-97).

Assim, como no ambiente da fábrica, no ambiente prisional é imposto ao sujeito moderno um adequar-se à temporalidade da pena - já que não se adequou à sociedade. Forja-se também um espaço alienante, para um sujeito alienado, que deixa de ter o direito de controlar o seu tempo. O apenado, na ótica prisional moderna, fica preso ao passado, que é o ponto no rio da história em que ele cometeu o crime (MORETTO, 2005, p.104-105).

$\mathrm{O}$ apenado é retirado abruptamente do seu ambiente de convívio e colocado em um ambiente hostil, estranho a ele, em que regras próprias de convívio são criadas e, a adaptabilidade a elas é uma exigência. Nesse espaço que é sempre o mesmo e, num tempo próprio desse espaço, o fluxo temporal do mundo mostra-se de forma inerte, devendo o sujeito viver esse tempo da prisão.

Deste modo, vislumbra-se a prisão como um espaço-tempo estranho à vida em sociedade, em que também estranhos são os que ali convivem. Cria-se assim uma harmonia própria e caótica que reordena - desordenando - o espaço-tempo do apenado no mundo, tornando-o um estranho entre os 
estranhos e, sobremodo, um estranho face à compreensão do "estar no tempo" em sociedade (BAUMAN, 2001, p.111-112).

A prisão, enquanto uma instituição total moderna seria pensada como um Espaço onde o Tempo linear - entendido como uma sucessão de eventos distintos rumo a um determinado fim - fica suspenso em nome de um Tempo cíclico, repetitivo. Nesta outra temporalidade, pretende-se que a introjeção de valores socialmente adequados permita que o interno seja "devolvido" ao fluxo do Tempo da sociedade com sua "dívida" quitada (LOBÃO, 2008, p.34).

Pretende-se assim, a ressocialização do indivíduo por meio de sua retirada do ambiente de convívio social, apartando-o da sociedade civilizada a qual não tem condição de pertencer no momento, colocando-o em meio a um ambiente anti-social, com regramentos de convívio próprios - diversos dos atinentes a sociedade civilizada - e de quase que total incivilização.

Neste passo, a pena de prisão traz em si um algo de memória e lembrança. $\mathrm{O}$ apenado mantém vivo o passado, enquanto no cumprimento da pena, ou seja, fica aprisionado no momento de cometimento do crime. Da mesma forma, esse sentimento memorial permanece futuramente, pois a estrutura social na qual ele é recolocado não o deixa esquecer o crime que cometeu como também, não o deixa rememorar - recuperar - o tempo transcorrido mundanamente (MESSUTI, 2003, p.113-114).

Assim, a civilização - vista enquanto ordem social dominante - impôs sua ânsia civilizatória, em face de um indivíduo que para civilizar-se se tornou um "banido" (a)temporal. Tal sentimento de estar fora do tempo é potencializado na sociedade contemporânea, fruto de uma aceleração na produção tecnológica, bem como, no modo de se relacionar socialmente.

$\mathrm{Na}$ sociedade pós-moderna o tempo, que antes era comandado pelas criações racionalizadoras da modernidade, passa a comandar o curso social, tornando irracional o estar no mundo. No entanto, o tempo que não mais está racionalizado pelas instituições político-jurídico-sociais, não inverte a lógica racionalizando-as, mas sim, criando um ambiente inóspito de desmantelamento dessas artificialidades erguidas pelo racionalismo moderno.

O acontecer social contemporâneo é um acontecer imediato, em tempo real, que provoca um sentimento de perda de tempo e, de aceleração dos compassos lentos da história. $\mathrm{O}$ ambiente neo-tecnológico impregna 
tudo e, assim, também o direito de um sentimento de necessidade pela resolução instantânea dos conflitos sociais. Pois este véu de instantaneidade perpassa todas as esferas do estar em sociedade, tornando o risco, o caos, a imperfeição, a incerteza, algo inerente ao sujeito contemporâneo (LOPES JUNIOR, 2004, p.165).

Assim, vive-se em uma época desmantelada pelo tempo tecnológico. O acontecer tecnológico é um acontecer acelerado e, ávido por recriação instantânea do que está posto - seja pela ciência, pela política, pelo direito, etc. A tecnologia transcende o ser meramente "técnica" e, avança por sobre a sociedade como um manto que a reveste, tornando-se valor desta nova sociedade - neo-tecnológica. E, nesta nova sociedade há uma reordenação dos espaços sociais, bem como, uma ruptura no modus social estratificado, hierarquizado dos "modernos" (BAUMAN, 2001, passim).

Neste tempo não mais sólido, impassível, passado, presente e futuro são reordenados valorativamente. O futuro, não é mais distante ou inimaginável, mas sim, torna-se algo palpável no meio tecnológico. Não se vive mais o tempo do hoje, mas sim, o tempo do amanhã. O hoje, em um piscar de olhos já não o é mais, mas não porque se tornou passado, mas sim, porque antes mesmo de passar já vislumbrou o "seu” futuro (D'MARAL, 2003, p.19-20).

Fica claro a inserção num tempo de transição e de ruptura paradigmática, e mesmo não tendo certeza sobre o que virá, sabe-se que o que se tinha antes, não mais tem lugar no mundo. É nítida a necessidade de se re-configurar todos os ambientes humanos, tornando-os mais humanos e, impedindo que haja uma perda de referencial de humanidade.

Deste modo, o sistema punitivo estabelecido deve ser revisto, de modo a adequar-se a uma temporalidade, que não é mais estática, mas sim efervescente. E, neste novo cenário, ao aprisionar-se o apenado em um tempo onde não é o seu, nem o da sociedade, está se gerando um descompasso abissal entre o tempo do ser prisional e o tempo do ser no mundo. Situação que não compactua com a instituição de um Estado Democrático de Direito, nem com a consolidação dos Direitos HumanoFundamentais. Para tanto, possibilidades se afiguram e, é o monitoramento eletrônico uma delas, sendo a explanação do próximo momento. 


\section{DO CONTROLE DO TEMPO AO TEMPO DO CONTROLE: O CASO DO MONITORAMENTO ELETRÔNICO}

Neste trilhar, a sociedade neo-tecnológica, complexa por excelência, deflagra um estado de urgência punitiva - punitivista -, que vê na penalização através de penas privativas de liberdade e, o consequente encarceramento, como um verdadeiro standard punitivo servil a qualquer caso. O que provoca um agigantamento do sistema de controle social - penal -, que ao adentrar na sociedade neo-tecnológica, passa de uma prática de controle do tempo, a um verdadeiro tempo do controle (CALLEGARI, 2010, p.337-355).

Neste cenário, o monitoramento eletrônico pode e deve ser visto como condição de possibilidade, para a resignificação do aparato punitivo no caminho de um verdadeiro Estado Democrático de Direito. No entanto, o sistema penal-criminal como um todo - Direito Penal, Processo Penal, Criminologia, etc - deve se resignificar encontrando um sentido constitucional de aplicabilidade que, acima de tudo, deve pautar-se pelo respeito aos direitos humano-fundamentais.

Porém, o que se nota, é uma ampliação cada vez maior do sistema de controle social - penal - e com isso, ocorre a consequente inserção do monitoramento eletrônico nesse meio, como um mecanismo de potencialização do sistema. $\mathrm{Na}$ ótica do aparato jurídico-penal posto, o monitoramento serviria para melhor vigiar os apenados que, devido à lógica do sistema, devam ser postos em liberdade.

Há um claro retrocesso, pois o monitoramento eletrônico está sendo tratado como possibilidade de que, contudo o apenado alcançar condições para libertar-se do regime prisional - progressão para o regime semi-aberto, liberdade condicional, prisão domiciliar, etc. - ele siga sendo vigiado, pela utilização do aparato eletrônico de vigilância. Em outras palavras, mesmo alcançando a semi-liberdade, o que acontece é do apenado ser - será mantido em um estado de permanente vigilância (AMARAL, 2010, p.7589).

Assim, em meio à sociedade de risco (BECK, 2010) aumenta o clamor por justiça - punição - e a malha prisional se vê reforçada. A ânsia punitiva é a marca de uma sociedade que, envolta em medos, busca no aprisionamento a redenção para os seus perigos e condutas dessocializadoras. $\mathrm{O}$ homem contemporâneo quer proteger-se ainda, mas não mais se enjaulando, pois 
pretende agora, enjaular o outro, ser social transgressor que ameaça a sua ordem na sociedade.

O monitoramento deve sim, ser visto como um possibilitador para a redução da distância tempo do cárcere e tempo social, já que, o cárcere busca manter o apenado preso a um tempo que rapidamente se apresenta obsoleto, mas ao qual, o apenado deve estar aferrado psicologicamente. O tempo da/na prisão é irrecuperável pelo sujeito, pois quando devolvido ao "tempo social", este, não mais será o tempo do cometimento do crime ao qual o apenado esteve preso - temporalmente (MORETTO, 2005, p.98).

O sistema penal - de controle penal/social - vigente deve ser solapado por uma nova sistemática punitiva. Não há mais espaço neste mundo, para as dualidades metafísicas - bem e mal, homem bom e homem ruim, bárbaro e civilizado, etc. - que marcaram a construção de toda a sistemática punitivista moderna. O homem contemporâneo não mais é, do que um ser compreendido e apreendido em sua finitude é ser humano e não perde tal condição ao cometer um crime (CARVALHO, 2008, p.41-45).

Assim, o monitoramento eletrônico pode ser o caminho para um novo quadro do sistema punitivo. Ao aplicar o monitoramento como medida não encarceradora, em primeiro lugar, está se evitando a retirada do indivíduo do seu ciclo espaço-temporal. A utilização do monitoramento como forma de não prender alguém que, seria preso, permite não quebrar a simetria temporal, tempo do cárcere-tempo social, mantendo um "criminoso" em seu tempo, mesmo que punido (HAUCK, 2005, p.50-66).

$\mathrm{O}$ apenado tem o direito de libertar-se do passado, em respeito pela dignidade da pessoa humana, de seguir no tempo da sociedade, na velocidade e aceleração que essa se desloca. Somos todos, quem tenha cometido um delito ou não, filhos da flecha do tempo e do caos, e isso não nos é permitido dispor ao Estado (MORETTO, 2005, p.99).

Sob este ponto de vista, cabe utilizar o controle eletrônico para inverter a lógica do discurso resocializador. A ressocialização, como atributo da pena é uma das bases à defesa do sistema carcerário. No entanto, a ordem desse discurso é dessocializar para ressocializar, parecendo evidente que, ao tirarse o apenado do convívio comunitário, mais difícil será (re)inseri-lo naquela comunidade passados cinco, dez, quinze anos. 
Assim, surgiria o monitoramento eletrônico como importante instrumento, como alternativa à retirada do "criminoso" da sociedade. O apenado cumpriria sua pena estando inserido no tecido social, podendo conviver com sua família, manter os laços comunitários, trabalhar, ou seja, ser parte da sociedade e, não, mais um excluído do sistema (HAUK, 2008, p.50-66).

De outro lado, antes mesmo de instituir-se o controle eletrônico de apenados, como efetiva medida para o desencarceramento, se faz necessário (re)adequar o quantum de pena à lógica temporal da sociedade contemporânea. A sociedade que vive sob o signo da virtualidade, é a sociedade em que a velocidade e a aceleração pontuam todos os âmbitos do acontecer social.

A inventividade tecnológica não cessa, as descobertas científicas revolucionam o mundo a cada mês, a cada semana, o tempo da/na internet é o tempo da comunicabilidade e convívio instantâneos, o ser na rede, é um ser atemporal. Logo, a pena enquanto tempo no/do cárcere, deve ser readequada proporcionalmente ao tempo neo-tecnológico, ao tempo digital. (MESSUTI, 2003, passim).

Quanto menos tempo - dentro de uma "nova" proporcionalidade crime-pena - o apenado manter-se alijado do processo de interação social, mais benéfico será para ele, do ponto de vista de reinserção social. Assim, mesmo nos crimes em que não será possível abandonar o encarceramento em prol do controle eletrônico, a duração da pena deve ser revista, em um mundo onde a "duração" é cada vez mais ínfima. A lógica temporal da pena no atual contexto social deve ser a de manter o apenado ligado ao presente e com olhos no futuro, ao invés de mantê-lo adstrito ao "tempo criminoso" - criminal (MORETTO, 2005, p.101).

Deve-se ao invés de potencializar, reduzir-se o sentimento de perda de tempo tão comum na sociedade contemporânea. O risco, a incerteza, o caos, abalam as estruturas da vida social, mas o que abala ainda mais é a perda de tempo. É melhor conviver com o risco, do que perder tempo tentando reduzi-lo, pois o tempo urge, e o estar no tempo é necessário para fazer parte deste novo caldo social. Ao apenado, deve então ser concedido o "risco" de manter-se em sociedade e, não a certeza de estar excluído do jogo (LOBÃO, 2008, passim).

Por óbvio, a utilização de tal aparato tecnológico não poder servir para aumentar o movimento de estigmatização do apenado. O estigma que 
acompanhará o apenado até mesmo após o cumprimento da pena, não se dá - pelo menos somente - pela sua condição de ter cumprido pena, mas sim, em muito, pela condição de ser alguém que já cometeu um crime.

Com o uso efetivo do monitoramento, o apenado não deixará de ser "criminoso", mas, além de não trazer consigo o estigma de ter sido encarcerado, poderá ter relativizada a marca feita em si de alguém que é criminoso, pois foi retirado do meio social. Com o uso do aparato eletrônico, sequer será retirado de sua família.

Evidente, que assim como o uso do controle eletrônico pode beneficiar o apenado, pode também marca-lo mais fortemente como um "ser desviante", que carrega em si a marca de sua própria punição - a pulseira, ou tornozeleira - provocando até mesmo, um "estado de alerta social” a respeito de sua pessoa.

\section{CONCLUSÃO}

Fica evidente a necessidade de rever os paradigmas jurídicos sobre os quais se assentaram as instituições jurídicas modernas, que lançam suas amarras ao Direito até os dias atuais. O Direito não mais pode ser visto como uma racionalidade técnica alienada e alienante, mas sim, como algo que está no mundo, envolto pela complexidade social e, que, por tal motivo, deve sofrer seus influxos.

O sistema penal nesse cenário deve ser revisto urgentemente, não só enquanto aparato jurídico-processual, bem como, enquanto operacionalidade punitivista, devendo ser relido o aparato punitivo quanto ao sistema de penas, quanto ao cumprimento destas e à penosidade temporal a qual é imposta ao apenado.

E, é neste talante, que o monitoramento eletrônico será visto como um meio apto a racionalizar humanitariamente o sistema de controle penal - social - e, de recolocar a pena - de prisão - no rio da história, no transcurso do tempo, como uma possibilidade, não a única, nem a melhor, apenas uma possibilidade a ser tratada como ultima ratio.

Deste modo, o paradigma punitivo, que nos é devido, não mais pode trazer em si um sentido de vingança punitivista estatal, mas sim, deve ser humanizado ao seu máximo, sendo perpassado por uma teoria dos direitos humano-fundamentais. Dessa forma, se garante um padrão mínimo de humanidade não só estrutural, mas temporal à pena e, ao seu cumprimento. 
O controle eletrônico dos apenados pode sim ser condição de possibilidade para essa humanização do cumprimento da pena. No entanto, não pode ser inserido no discurso dominante, que visa aumentar o controle através do monitoramento com a pretensa intenção de desencarcerar. $\mathrm{O}$ monitoramento eletrônico não pode, de maneira alguma, ser veículo para o aumento da malha punitivista e, para a transformação paradigmática maléfica, de sociedade de controle do tempo, para uma sociedade em que se viva um tempo do/de controle.

Assim, não mais se desloca o apenado espaço-temporalmente. Permite-se seguir em seu tempo, não dessocializando-o para ter que, em momento posterior, ressocializar e, relativizar o estigma de alguém que cometeu um crime traz consigo. Isso se dá pautado por um sentimento de proteção e concretização de direitos, bem como, por um sentimento de humanização tecnológico e, não, de tecnologicização do humano.

\section{REFERÊNCIAS}

ALVES, Daniela Alves de. Gestão, Produção e Experiência do Tempo no Teletrabalho. Porto Alegre: UFRGS, 2008, 246 p. Tese (Doutorado) Programa de Pós-Graduação em Sociologia, Instituto de Filosofia e Ciências Humanas, Universidade Federal do Rio Grande do Sul, Porto Alegre, 2008.

AMARAL, Augusto Jobim do. Entre Serpentes e Toupeiras: a cultura do controle na contemporaneidade (ou sobre o caso do monitoramento eletrônico de presos no Brasil. Sistema Penal e Violência, Porto Alegre, V. 2, N. 2, p.75-89, jul-dez. 2010.

BAUMAN, Zygmunt. Modernidade Líquída. Rio de Janeiro: Jorge Zahar, 2001.

BECK, Ulrich. Sociedade de Risco - rumo a uma outra sociedade.

São Paulo:Editora 34, 2010.

CALLEGARI, André Luis; WERMUTH, Maiquel Ângelo Dezordi. Medo, Direito Penal e Controle Social. Pensar, Fortaleza, V. 15, N. 2, p.337-355, Jul-Dez .2010. 
CARVALHO, Salo de. Anti-Manual de Criminologia. Rio de Janeiro: Lumen Juris, 2008.

D'MARAL, Marcio Tavares. Sobre Tempo: considerações intempestivas. In: DOCTORS, Marcio (Org). Tempo dos Tempos. Rio de Janeiro: Jorge Zahar, 2003.

ELIAS, Norbert. Sobre O Tempo. Rio de Janeiro: Jorge Zahar, 1998.

FOUCAULT, Michel. Vigiar e Punir: história da violência das prisões. Petrópolis: Vozes, 1994.

GAUER, Ruth M. Chittó. Conhecimento e Aceleração (mito, verdade e tempo). In: GAUER, Ruth M. Chittó (Org). A Qualidade do Tempo: para além das aparências históricas. Rio de Janeiro: Lumen Juris, 2004.

HAUCK, João Ricardo. Tecnociência, Vigilância e Sistema Penal: a superação de paradigmas e as novas perspectivas sob o viés tecnológico. Direito e Justiça, Porto Alegre, V. 34, N. 2, p.50-66, jul-dez. 2008.

JUNIOR, Aury Lopes. (Des)Velando o Risco e o Tempo no Processo Penal. In: GAUER, Ruth M. Chittó (Org). A Qualidade do Tempo: para além das aparências históricas. Rio de Janeiro: Lúmen Júris, 2004.

KLEIN, Étienne. O Tempo. Lisboa: Instituto Piaget, 1995.

LOBÃO, Ronaldo. O Tempo Vertiginoso: impossível de se capturar na lei?. Revista da Secretaria de Justiça do Rio de Janeiro, No 22 , Rio de Janeiro, 2008.

MESSUTI, Ana. O Tempo Como Pena. São Paulo: Revista dos Tribunais, 2003.

MORAIS, José Luis Bolzan de. A Subjetividade do Tempo: uma perspectiva transdisciplinar do direito e da democracia. Porto Alegre: Livraria do Advogado, 1998. 
MORETTO, Rodrigo. Crítica Interdisciplinar da Pena de Prisão: controle do espaço na sociedade do tempo. Rio de Janeiro: Lumen Júris, 2005.

PINTO, Cristiano Paixão Araújo. Modernidade, Tempo e Direito. Belo Horizonte: Del Rey, 2002.

Submetido em: 10/03/2013 Aprovado em: 08/07/2013

Como citar: CAVALHEIRO, Larissa Nunes; HOFFMAM, Fernando; DE OLIVEIRA, Rafael Santos. O controle do tempo como condição de possibilidade para o sistema de controle penal na sociedade neo-tecnológica. Scientia Iuris, Londrina, v.17, n.1, p.161178, jul.2013. DOI: 10.5433/2178-8189.2013v17n1p161. 